УДК 504.53:579.26

\title{
Laboratory Research of Degradation of Polyhydroxyalkanoates of Different Chemical Structure in Soil
}

\author{
Olga N. Vinogradova* and Daria A. Syrvacheva \\ Institute of Biophysics of SB RAS \\ 50/50 Akademgorodok, Krasnoyarsk, 660036, Russia
}

Received 14.01.2015, received in revised form 16.02.2015, accepted 22.04.2015

Degradation of three types of polyhydroxyalkanoates (PHAs) was studied in the laboratory conditions in the field soil at two temperature regimes during 35 days. It was shown that composition of PHA and the degree of crystallinity have a significant effect on degradation of PHA films. The order of biodegradability of film samples was: poly-3-hydroxybutyrate-co-4-hydroxybutyrate (P3HB-co-4HB) $>$ poly-3-hydroxybutyrate-co-3-hydroxyvalerate $(\mathrm{P} 3 \mathrm{HB}-\mathrm{co}-3 \mathrm{HV})>$ poly-3-hydroxybutyrate (P3HB). Samples of P3HB-co-4HB copolymers with the lowest degree of crystallinity were destroyed most actively; a significant decrease of molecular weight of P3HB-co-4HB during destruction was found. The initial molecular weight of the samples did not affect the process of PHA destruction. A significant effect of the medium temperature on the rate of PHA degradation was found; PHA samples were destroyed 1.5-2 times more actively at $28^{\circ} \mathrm{C}$ compared to $21{ }^{\circ} \mathrm{C}$.

Keywords: degradable biopolymers, polyhydroxyalkanoates (PHAs), copolymers, 3-hydroxybutyrate, 4-hydroxybutyrate, 3-hydroxyvalerate, biodegradation in the soil.

DOI: $10.17516 / 1997-1389-2015-8-2-210-219$.

(c) Siberian Federal University. All rights reserved

* Corresponding author E-mail address: olgav88@mail.ru 


\title{
Лабораторные исследования
}

\section{деградации полигидроксиалканоатов \\ различной химической структуры в почве}

\author{
О.Н. Виноградова, Д.А. Сырвачева \\ Институт биофизики СО РАН \\ Россия, 660036, Красноярск, Академгородок, 50/50
}

Исследована деградачия трех типов полигидроксиалканоатов (ПГА) в лабораторных условиях в полевой почве при двух температурных режимах в течение 35 суток. Показано существенное влияние состава мономеров и степени кристалличности ПГА на разрушаемость в лабораторных почвенных микроэкосистемах. Пленочные образиы поли-3гидроксибутирата (ПЗГБ), поли-3-гидроксибутирата/4-гидроксибутирата (ПЗГБ/4ГБ), поли3-гидроксибутирата/3-гидроксивалерата (ПЗГБ/ЗГВ) по активности разрушения в почве расположены в ряду: ПЗГБ/4ГБ > ПЗГБ/ЗГВ > ПЗГБ. Наиболее активно разрушаются образиь сополимеров ПЗГБ/4ГБ, имеющие самую низкую степень кристалличности, для которых зарегистрировано значительное падение молекулярной массы по мере разрушения. Влияния исходной величины молекулярной массы образиов на процесс разрушения ПГА не обнаружено. Подтверждено существенное влияние температуры среды на активность разрушения ПГА; при $28{ }^{\circ} \mathrm{C}$ образиы ПГА разрушаются в 1,5-2 раза активнее, чем при $21{ }^{\circ} \mathrm{C}$.

Ключевые слова: разрушаемые биополимеры, полигидроксиалканоаты (ПГА), сополимеры, 3-гидроксибутират, 4-гидроксибутират, 3-гидроксивалерат, биодеградация в почве.

\section{Введение}

Наращивание объемов производства и применение микробных биопластиков разрушаемых полигидроксиалканоатов (ПГА) - делает необходимым активизацию исследований закономерностей их разрушения в природных средах с учетом различий географических и погодно-климатических условий. К настоящему времени исследована разрушаемость в основном двух представителей этого класса биополимеров гомогенного поли-3-гидроксибутирата (ПЗГБ) и сополимеров 3-гидроксибутирата c 3-гидроксивалератом (ПЗГБ/ЗГВ) (Doi et al., 1992; Mergaert et al., 1995; Tomasi et al., 1996).
Большой вклад в изучение разрушаемости ПГА внесли исследования, проводимые в Институте биофизики СО РАН и Сибирском федеральном университете. В течение ряда лет изучались закономерности биоразрушения ПЗГБ и ПЗГБ/ЗГВ в виде пленок и прессованных 3D-форм в реальных природных условиях - в водных и почвенных экосистемах, различающихся структурой микробиоценозов. Исследования проведены в пресноводных водоемах (Volova et al., 2004; 2006; 2007) и почвах сибирского региона (Прудникова и др., 2012; Воyandin et al., 2012a), солоноводном лечебном озере Шира (Жила и др., 2012), в тропических условиях: в Южно-Китайском мope (Volova et al., 2010; 2011; Boyandin et al., 
2013), материковых и прибрежных почвах (Прудникова и др., 2012; Boyandin et al., 2013). Обобщением этих исследований стало издание монографии «Экологическая роль полигидроксиалканоатов: закономерности биоразрушения в природной среде и взаимодействия с микроорганизмами» (Прудникова, Волова, 2012).

Полигидроксиалканоаты - это семейство полимеров различной химической структуры, свойства которых значительно варьируют (Laycock et al., 2013; Chen et al., 2001). Вариабельность химической структуры и вытекающая из этого вариабельность физикохимических свойств оказывает влияние также и на процессы биоразрушения этих полимеров (Steinbuchel, 2001; Williams et al., 1999; Freier et al., 2002; Na et al., 2003; Janigova et al., 2002; Aoyagi et al., 2002; Tsuji, Suzuyoshi, 2002; He et al., 2001).

Особо перспективными, но трудносинтезируемыми ПГА являются сополимеры, обладающие свойствами эластомеров, содержащие в своем составе помимо 3-гидроксибутирата (ЗГБ) мономеры 4-гидроксибутирата

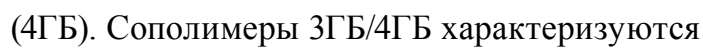
более низкими значениями степени кристалличности, температуры плавления и термической деградации (Volova et al., 2014). В литературе известны лишь единичные работы по изучению деградации сополимеров этих типов (Wen, Lu, 2012; Weng et al., 2011; Salim et al., 2012), показавшие, что скорости разрушения ПЗГБ/4ГБ существенно превосходят таковые у ПЗГБ и ПЗГБ/3ГВ (Weng et al., 2011; Salim et al., 2012).

В настоящей работе впервые в сравнительном аспекте исследована кинетика биоразрушения трех представителей ПГА, различающихся химическим строением и базовыми физико-химическими свойствами, в лабораторных почвенных микроэкосистемах.

\section{Материалы и методы}

Исследованы образцы полигидроксиалканоатов, синтезированные в культуре бактерий Cupriavidus eutrophus B10646 в лаборатории хемоавтотрофного биосинтеза Института биофизики СО РАН по авторской технологии (Volova et al., 2013, 2014): гомополимер поли-3-гидроксибутират (ПЗГБ) и сополимеры поли(3-гидроксибутирата/3гидроксивалерата) (ПЗГБ/ЗГВ) с включением 3-гидроксивалерата 32 мол. \% и поли(3гидроксибутирата/4-гидроксибутирата) (ПЗГБ/4ГБ) с включением 4-гидроксибутирата 35 мол. \%. Различия химической структуры образцов ПГА показаны на рис. 1.

Исследованы образцы в виде пленок, полученных методом полива из растворов полимеров в хлороформе. Гомогенные растворы, содержащие 40 г/л полимера, нагретые до $35{ }^{\circ} \mathrm{C}$, выливали на обезжиренную поверхность чашек Петри и высушивали в течение 2-3 суток при комнатной температуре в ламинарном боксе (Labconco, США) и досушивали до постоянного веса в десикаторе. Для экспериментов из пленок высекали диски диаметром 30 мм, толщиной $0,045 \pm 0,005$ мм, которые взвешивали на аналитических весах 1-го класса точности Discovery (Ohaus, Швейцария).

Взвешенные образцы ПГА помещали в нейлоновые сетки и размещали по 3 штуки в пластиковых контейнерах объемом $250 \mathrm{~cm}^{3}$ с полевой почвой (200 г) на глубину 2 см. Полевая почва (Красноярский край, пос. Минино) - агрочернозем криогенномицеллярный, характеризуется высоким содержанием гумуса, слабощелочной реакцией среды (pH 7,1-7,8). Плотность почвы имеет рыхлое и нормальное сложение пахотного слоя $\left(0,85-1,11\right.$ г/см $\left.{ }^{3}\right)$. Общий титр органотрофных бактерий составил $16,3 \pm 5,1$ млн КОЕ в 1 г. 


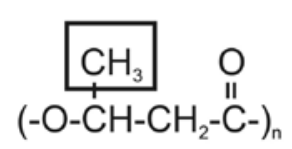

ПЗГБ

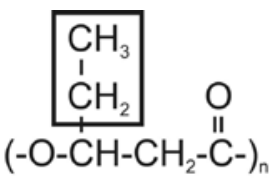

ПЗГБ/ЗГВ<smiles>O=CCCC[Cr]=O</smiles>

ПЗГБ/4ГБ

Рис. 1. Структурные формулы исследованных представителей ПГА

Длительность экспозиции полимерных пленок в почве составила 35 суток при двух температурных режимах - 21 и $28{ }^{\circ} \mathrm{C}$; абсолютной влажности почвы - 50 \%. Уменьшение массы образцов определяли в динамике с периодичностью в 7 дней, для этого образцы ПГА (по 3 шт.) изымали из почвы. Одновременно с отбором проб ПГА регистрировали рН и влажность почвы с использованием стандартных физико-химических методов (Звягинцев, 1990). Образцы после изъятия из почвы отмывали от земли дистиллированной водой, помещали в термостат при $40{ }^{\circ} \mathrm{C}$ на 24 ч для высушивания до постоянного веса, далее пленки взвешивали.

Показателями биодеградации ПГА служили: убыль массы образцов, изменение молекулярно-массовых характеристик, степени кристалличности; морфология и свойства поверхности.

Молекулярно-массовые характеристики образцов ПГА исследовали методом гель-проникающей хроматографии (модель 1260 Infinity, «Agilent Technologies», США) с детектором показателя преломления, используя колонку Agilent PLgel Mixed-C. Определяли средневесовую $\left(\mathrm{M}_{\mathrm{B}}\right)$ и среднечисловую молекулярную массу $\left(\mathrm{M}_{4}\right)$ и полидисперсность (Đ), позволяющую оценить соотношение в полимере фрагментов с различной степенью полимеризуемости. Определение степени кристалличности образцов проводили на рентгеноспектрометре D8 ADVANCE (Bruker, Германия). Степень кристалличности $\left(\mathrm{C}_{\mathrm{x}}\right)$ вычисляли как соотношение общей площади кристаллических пиков к общей площади радиограммы (кристалличные + аморфные компоненты). Термический анализ проведен с использованием дифференциально-сканирующего калориметра DSC-1 (METTLER TOLEDO, Швейцария). Температуру плавления и термической деградации определяли по экзотермическим пикам на термограммах. Термограммы анализировали с помощью программного обеспечения STARe v11.0 (METTLER TOLEDO, Швейцария).

Статистическую обработку результатов осуществляли общепринятыми методами с использованием стандартного пакета программ Microsoft Excel. Результаты представлены как средние арифметические со стандартным отклонением.

\section{Результаты и обсуждение}

Исследованные образцы ПГА отличались по физико-химическим свойствам (табл. 1). Наиболее существенные отличия исследованных образцов - различия степени кристалличности. Самая высокая степень кристалличности (76 \%) характерна для гомополимера ПЗГБ; у сополимера ЗГБ/ЗГВ - существенно ниже (51\%), а у сополимера 3ГБ/4ГБ - еще ниже (39 \%). Самые высокие и близкие значения молекулярно-массовых характеристик были у ПЗГБ и сополимера $3 Г Б / 3 Г В ~\left(М_{в} 920\right.$ и 1120 кДа); у сополимера 3 Б/4ГБ - ниже практически в 2 раза (597 кДа). Полидисперсность 
Таблица 1. Состав и физико-химические свойства полимерных образцов ПГА, экспонированных в почве

\begin{tabular}{|c|c|c|c|c|c|c|c|c|c|}
\hline \multirow{2}{*}{$\begin{array}{c}\text { Номер } \\
\Pi / \Pi\end{array}$} & \multicolumn{3}{|c|}{ Состав ПГА, мол. \% } & \multirow{2}{*}{$\mathrm{M}_{\text {ч }}, \kappa Д а$} & \multirow{2}{*}{$\mathrm{M}_{\mathrm{B}}$, кДа } & \multirow{2}{*}{$Đ$} & \multirow{2}{*}{$\mathrm{C}_{\mathrm{x}}, \%$} & \multirow{2}{*}{$\mathrm{T}_{\text {плл}},{ }^{\circ} \mathrm{C}$} & \multirow{2}{*}{$\mathrm{T}_{\text {дегр, }},{ }^{\circ} \mathrm{C}$} \\
\hline & 3ГБ & 4 4ГБ & $3 \Gamma \mathrm{B}$ & & & & & & \\
\hline 1 & 100 & 0 & 0 & 365 & 920 & 2,52 & 76 & 178 & 295 \\
\hline 2 & 65 & 35 & 0 & 149 & 597 & 4,00 & 39 & 167 & 280 \\
\hline 3 & 68 & 0 & 32 & 460 & 1120 & 2,00 & 51 & 177 & 284 \\
\hline
\end{tabular}

Примечание: $\mathrm{M}_{4}$ - среднечисловая молекулярная масса, $\mathrm{M}_{\mathrm{B}}$ - средневесовая молекулярная масса, Đ - полидисперсность, $\mathrm{C}_{\mathrm{x}}$ - степень кристалличности, $\mathrm{T}_{\text {пл }}$ - температура плавления, $\mathrm{T}_{\text {дегр }}$ - температура термической деградации.

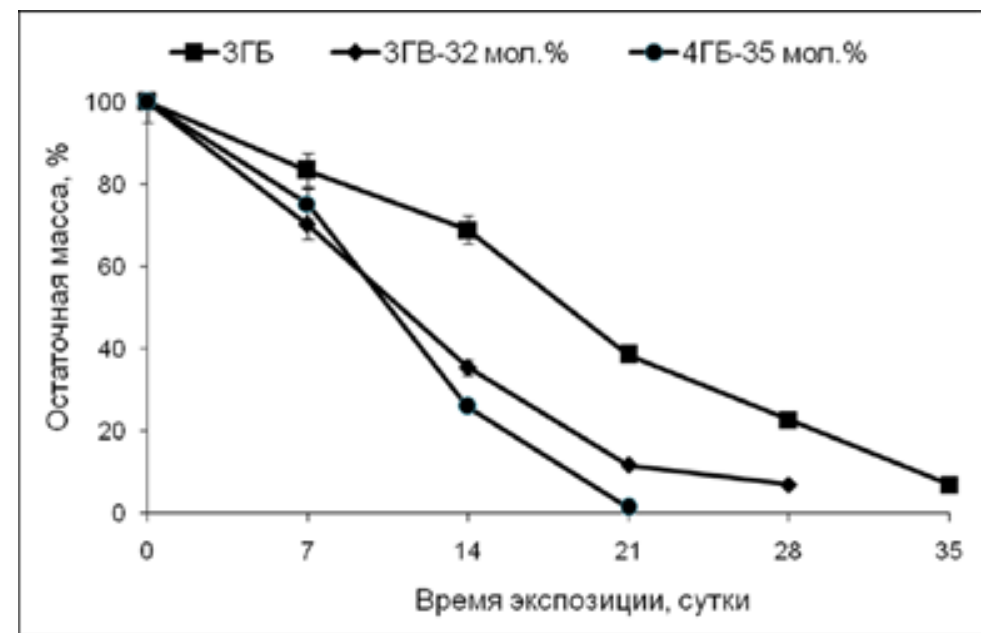

Рис. 2. Динамика уменьшения массы образцов пленок, полученных из ПГА различного химического состава, в почве при $28^{\circ} \mathrm{C}$

исследуемых образцов также менялась от 2,0 до 4,0 в зависимости от состава ПГА.

Различия химической структуры и свойств оказывали влияние на кинетику разрушения ПГА (рис. 2). При $28{ }^{\circ} \mathrm{C}$ (эта температура выбрана с учетом известных данных о том, что она является оптимальной для максимальной разрушаемости ПГА) (Волова и др., 1998) в течение первых 7 суток отмечена убыль массы всех пленочных образцов; наиболее выражено на $30 \%$ от исходной у ПЗГБ/4ГБ, в меньшей степени (на $10 \%$ - у ПЗГБ.

Далее наступала фаза интенсивной деструкции, в ходе которой масса образцов убывала более активно. Установлено, что наиболее подвержены разрушению пленки из

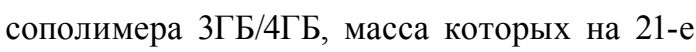
сутки экспозиции была разрушена на $97 \%$ от исходной. В эти сроки масса гомополимера уменьшилась на $60 \%$, и только на 35-е сутки зафиксировано разрушение ПзГБ на $93 \%$. Разрушаемость сополимера 3ГБ/ЗГВ была сопоставимой и занимала промежуточное положение между быстро разрушаемым ПЗГБ/4ГБ и медленно разрушаемым ПЗГБ. Таким образом, три исследованных типа ПГА по скорости разрушаемости при $28^{\circ} \mathrm{C}$ в почве можно расположить следующим образом: ПЗГБ/4ГБ $>$ ПЗГБ/ЗГВ > ПЗГБ.

Внешний вид пленок гомополимера ПЗГБ

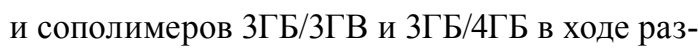




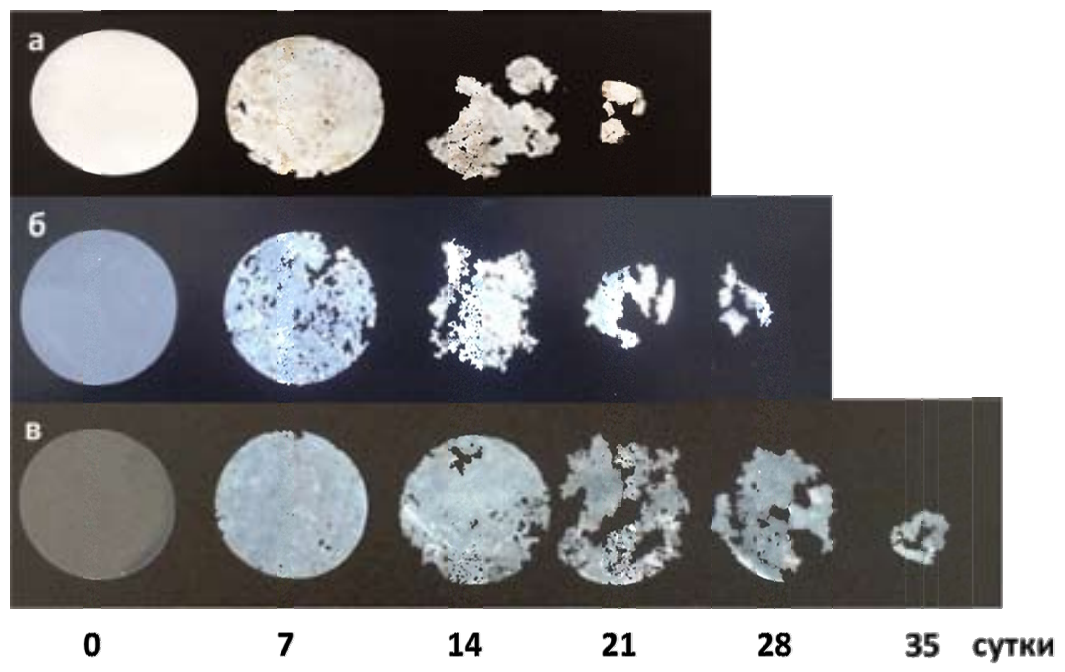

Рис. 3. Внешний вид пленок из ПГА в ходе разрушения в почве при $28{ }^{\circ} \mathrm{C}$ : a - ПЗГБ/4ГБ; б - ПЗГБ/3ГВ; в - ПЗГБ

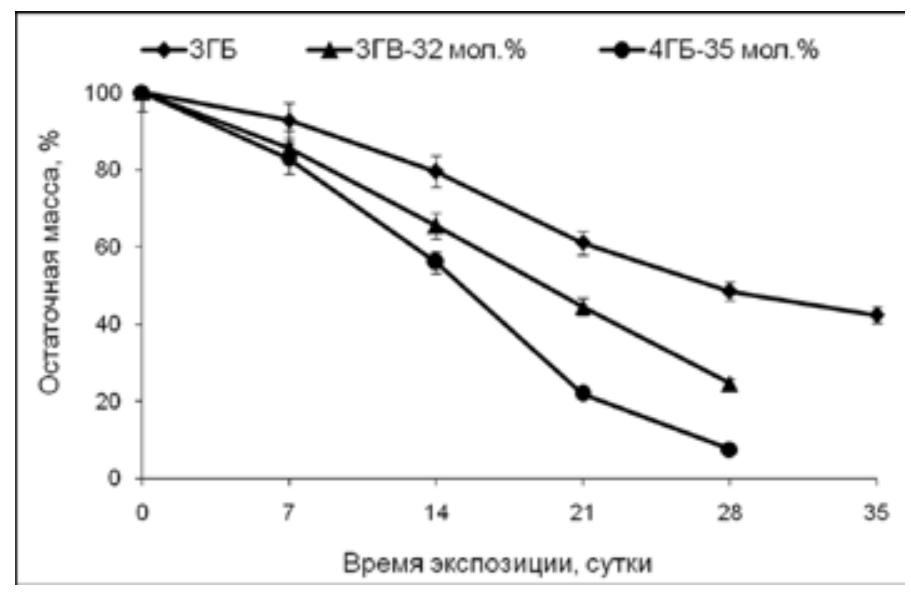

Рис. 4. Динамика уменьшения массы образцов пленок, полученных из ПГА различного химического состава, в почве при $21{ }^{\circ} \mathrm{C}$

рушения при температуре $28{ }^{\circ} \mathrm{C}$ показан на рис. 3.

При снижении температуры почвы до $21{ }^{\circ} \mathrm{C}$ разрушение всех образцов происходило менее активно (рис. 4 и 5).

За первые 7 суток зафиксировано разрушение всех образцов, но убыль массы была практически в 2 раза ниже, чем при $28^{\circ} \mathrm{C}$. При этом влияние состава ПГА на интенсивность биодеградации была аналогичной.
Пленки из ПЗГБ/4ГБ разрушились к 28-м суткам практически на 90 \%; из ПЗГБ/ЗГВ на $75 \%$ от исходной массы. И только пленки из гомополимера ПЗГБ разрушались медленно. Эти образцы разрушились только на 60 \% на 35-е сутки эксперимента.

Вычисленные значения скорости разрушения ПГА дали следующие показатели: при $21{ }^{\circ} \mathrm{C}$ в среднем убыль массы образцов гомополимера ПЗГБ составляла 1,57 мг/сут, у 


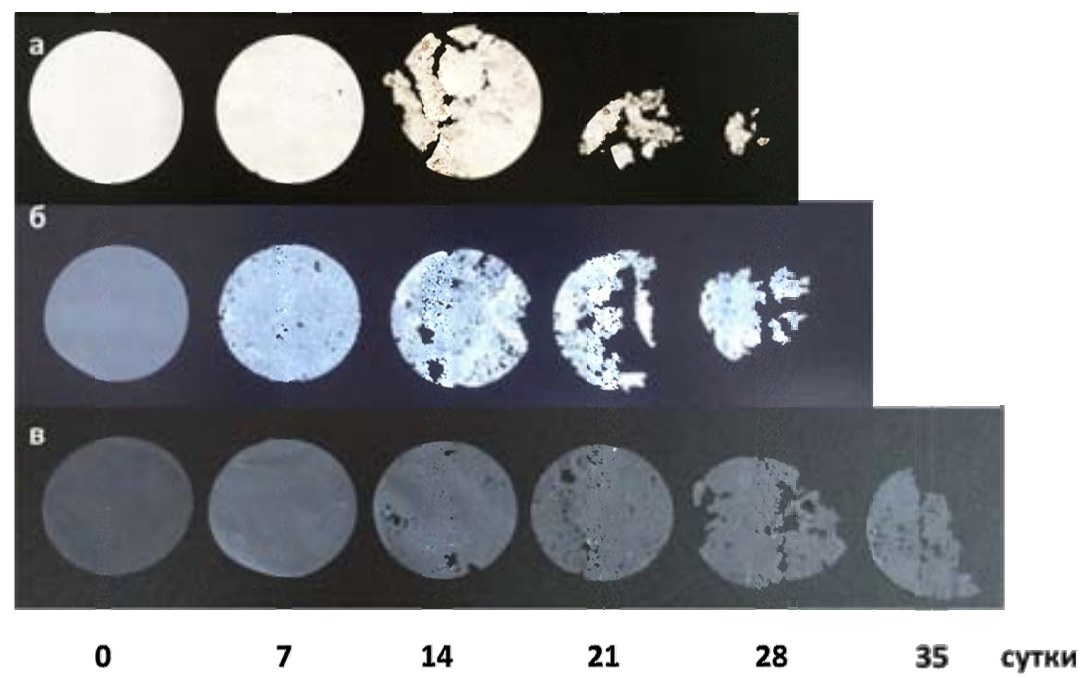

Рис. 5. Внешний вид пленок из ПГА в ходе разрушения в почве при $21{ }^{\circ} \mathrm{C}$ : a - ПЗГБ/4ГБ; б - ПЗГБ/3ГВ; в - ПЗГБ

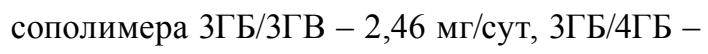
3,15 мг/сут. При $28{ }^{\circ} \mathrm{C}$ убыль массы образцов ПГА была на $40 \%$ выше и составила у ПЗГБ 2,58 мг/сут, у ПЗГБ/3ГВ - 4,08 мг/сут и у ПЗГБ/4ГБ - 4,5 мг/сут.

Как известно, на скорость деградации ПГА влияет степень кристалличности, чем она ниже, т.е. выше объем неупорядоченной (аморфной) фазы в полимере, тем активнее разрушается полимер (Kunioka et al., 1989). Полученные результаты согласуются с этим положением. Наиболее активно разрушаемые образцы ПЗГБ/4ГБ исходно имели самую низкую кристалличность; и, напротив, наиболее кристалличные образцы гомополимера ПЗГБ разрушались менее активно. Образцы ПЗГБ/ЗГВ, имеющие кристалличность выше, чем у ПЗГБ/4ГБ, и ниже, чем у ПЗГБ, по активности разрушения занимали промежуточное положение.

Результаты исследования степени кристалличности разрушенных образцов ПГА представлены на рис. 6. Степень кристалличности наименее разрушенных образцов ПЗГБ через 35 суток экспозиции в почве практически не изменилась. Это позволяет говорить о том, что в процессе разрушения этого типа ПГА обе фазы (кристаллическая и аморфная) разрушались равномерно. Степень кристалличности образцов сополимера ЗГБ/ЗГВ возрастала от исходной $51 \%$, при этом более отчетливо при $21{ }^{\circ} \mathrm{C}$ до $63 \%$, т.е. в данном случае более активно разрушалась аморфная фаза. Еще более выражен этот эф-

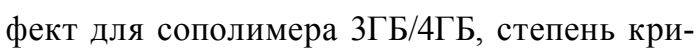
сталличности которых от исходной (39 \%) возросла до $50 \%$ при $28{ }^{\circ} \mathrm{C}$ и до $54 \%$ при $21{ }^{\circ} \mathrm{C}$.

Прямой связи между разрушаемостью образцов ПГА и исходными значениями молекулярной массы не выявлено. Однако обнаружено, что изменение этой величины в ходе разрушения пленок было различным. Величина средневесовой молекулярной массы медленно разрушаемого гомополимера ПЗГБ, а также сополимера ЗГБ/ЗГВ практически не изменялись, несмотря на значительную убыль массы. Однако у наиболее активно разрушаемого сополимера 3 ББ/3ГВ уже через 7 суток отмечено резкое снижение значений молекулярной массы и возрастание полидисперсности, однако далее продолжалось не- 


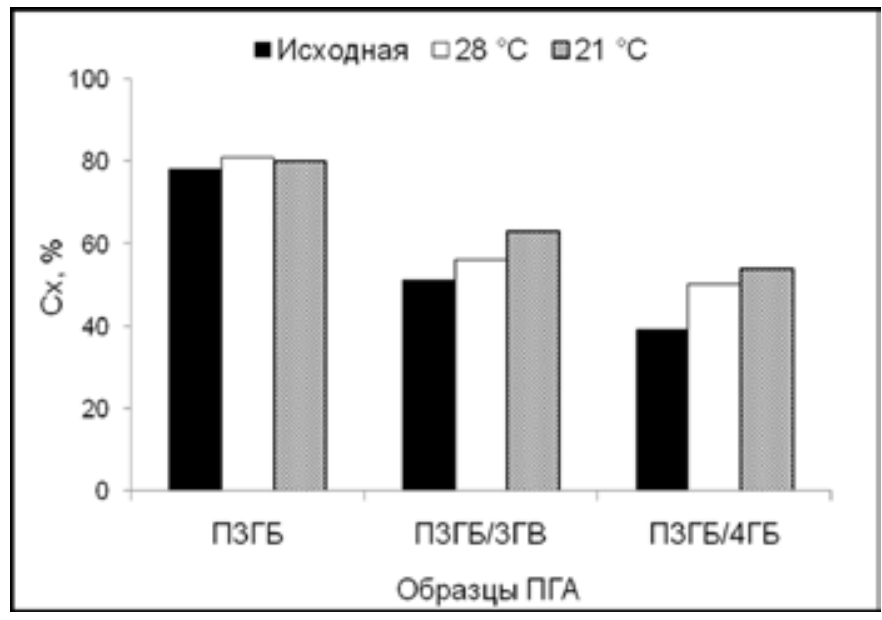

Рис. 6. Изменение степени кристалличности образцов ПГА в ходе разрушения в почве при различных температурных режимах

значительное снижение массы. Так, при экспонировании образцов при температуре $21{ }^{\circ} \mathrm{C}$ за первую неделю среднечисловая и средневесовая молекулярные массы снизились в 4 и 1,88 раза соответственно, а Ф возросла в 2,2 раза. К концу эксперимента эти значения составили 26 и 255 кДа соответственно. При $28{ }^{\circ} \mathrm{C}$ также за первую неделю происходило значительное снижение молекулярной массы, в 2 и 1,5 раза соответственно, и возрастание величины Đ в 1,4 раза.

\section{Заключение}

Таким образом, в ходе сравнительного исследования трех типов ПГА различной химической структуры в лабораторных по- чвенных микроэкосистемах показано существенное влияние состава мономеров и степени кристалличности ПГА на их разрушаемость. Наиболее активно разрушаются образцы сополимера ЗГБ/4ГБ, имеющие самую низкую степень кристалличности, для которых зарегистрировано значительное падение молекулярной массы по мере разрушения. По активности разрушения ПГА в почве образцы расположены в ряду: ПЗГБ/4ГБ > ПЗГБ/ЗГВ > ПЗГБ. Влияния исходной величины молекулярной массы образцов на процесс разрушения ПГА не обнаружено. Подтверждено существенное влияние температуры среды на активность разрушения ПГА.

Работа выполнена при поддержке гранта Российского научного фонда № 14-26-00039.

\section{Список литературы}

1. Волова Т.Г., Беляева О.Г., Плотников В.Ф., Пузырь А.П. (1998) Исследование биодеградации микробных полигидроксиалканоатов. Прикладная биохимия и микробиология 34 (5): 539-543 [Volova T.G., Belyaeva O.G., Plotnikov V.F., Puzyr’ A.P. (1998) Study of microbial biodegradable polyhydroxyalkanoates. Applied Biochemistry and Microbiology 34 (5): 539-543].

2. Жила Н.О., Прудникова С.В., Задереев Е.С., Рогозин Д.Ю. (2012) Деградация пленок из полигидроксиалканоатов в солоноватоводном озере Шира. Журнал СФУ 5 (2): 210-215 [Zhila 
N.O., Prudnikova S.V., Zadereev E.S., Rogozin D.Y. (2012) Degradation of polyhydroxyalkanoate films in brackish lake Shira. Journal of Siberian Federal University, Biology 5 (2): 210-215 (In Russian)].

3. Звягинцев Д.Г. (1990) Методы почвенной микробиологии и биохимии. М: МГУ, 303 с. [Zvyagintsev D.G. (1990) Methods of soil microbiology and biochemistry. M: MSU, 303 p.].

4. Прудникова С.В., Коробихина К.И., Бояндин А.Н., Волова Т.Г. (2012) Закономерности биоразрушения полигидроксиалканоатов на территории Вьетнама и Центральной Сибири. Журнал СФУ, Биология 5 (3): 311-321 [Prudnikova S.V., Korobikhina K.I., Boyandin A.N., Volova T.G. (2012) Biodegradation behavior of polyhydroxyalkanoates on the territory of Vietnam and Central Siberia. Journal of Siberian Federal University, Biology 5 (3): 311-321 (In Russian)].

5. Aoyagi Y., Yamashita K., Doi Y. (2002) Thermal degradation of poly[(R)-3-hydroxybutyrate], poly[epsilon-caprolactone], and poly [(S )-lactide]. Polym Degrad Stabil 76 (1): 53-59.

6. Boyandin A.N., Prudnikova S.V., Filipenko M.L., Khrapov E.A., Vasil'ev A.D., Volova T.G. (2012a) Biodegradation of polyhydroxyalkanoates by soil microbial communities of different structures and detection of PHA degrading microorganisms. Applied Biochemistry and Microbiology 48 (1): $28-36$.

7. Boyandin A.N., Prudnikova S.V., Karpov V.A., Ivonin V.N., Korobohina K., Filipenko M.L., Volova T.G., Sinskey A.J. (2012b) Microbial degradation of polyhydroxyalkanoates in tropical soils. Macromol. Symposium 320: 38-42.

8. Boyandin A.N., Prudnikova S.V., Karpov V.A., Ivonin V.N., Đỗ Ngọc Lanh, Nguyễn Thị Hoài, Lê Thị Mỹ Hiệp, Filipenko M.L., Volova T.G., Gitelson I.I. (2013) Microbial degradation of polyhydroxyalkanoates in tropical soils. International Biodeterioration \& Biodegradation 83: $77-84$.

9. Chen G.Q., Wu Q., Chen J.C. (2001) Biosynthesis of polyhydroxyalkanoate. Tsinghua J Sci Technol 6: 193-199.

10. Doi K., Kanesawa Y., Tanahashi N. (1992) Biodegradation of microbial polyesters in the marine environments. Polym Degrad Stab 36: 173-177.

11. Freier T., Kunze C., Nischan C., Kramer S., Sternberg K., Sass M. (2002) In vitro and in vivo degradation studies for development of a biodegradable patch based on poly (3-hydroxybutyrate). Biomaterials 23 (13): 2649-2657.

12. He Y., Shuai X.T., Cao A., Kasuya K., Doi Y., Inoue Y. (2001) Enzymatic biodegradation of synthetic atactic poly(R, S-3-hydroxybutyrate) enhanced by an amorphous nonbiodegradable polymer. Polym Degrad Stabil 73 (2):193-199.

13. Janigova I., Lacik I., Chodak I. (2002) Thermal degradation of plasticized poly(3-hydroxybutyrate) investigated by DSC. Polym Degrad Stabil 77 (1): 35-41..

14. Kunioka M., Kawaguchi Y., Doi Y. (1989) Production of biodegradable copolyesters of 3-hydroxybutyrate and 4-hydroxybutyrate by Alcaligenes eutrophus. Appl Microbiol Biotechnol 30 (6): 569-573.

15. Mergaert J., Wouters A., Swings J., Anderson C. (1995) In situ biodegradation of poly(3hydroxybutyrate) and poly(3-hydroxybutyrate-co-3-hydroxyvalerate) in natural waters. Can J Microbiol 41 (1):154-159. 
16. Na Y.H., He Y., Nishiwaki T., Inagawa Y., Osanai Y., Matsumura S. (2003) Phase-separation enhanced enzymatic degradation of atactic poly(R, S-3-hydroxybutyrate) in the blends with poly(methyl methacrylate). Polym Degrad Stabil 79 (3): 535-545.

17. Steinbuchel A. (1991) Polyhydroxyalkanoic acids. In: Byrom D. (ed) Biomaterials: novel materials from biological sources. New York: Stockton, p. 124-213.

18. Tomasi G., Scandola M., Briese B.H., Jendrossek D. (1996) Enzymatic degradation of bacterial poly(3-hydroxybutyrate) by a depolymerase from Pseudomonas lemoignei. Macromolecules 29 (2): 507-513.

19. Tsuji H., Suzuyoshi K. (2002) Environmental degradation of biodegradable polyesters 2 . Poly(epsilon-caprolactone), poly [(R)-3-hydroxybutyrate], and poly(L-lactide) films in natural dynamic seawater. Polym Degrad Stabil 75 (2): 357-365.

20. Voinova O.N., Gladyshev M.I., Volova T.G. (2008) Comparative study of PHA degradation in natural reservoirs having various types of ecosystems. Macromol Symposia 269: 34-37.

21. Volova T.G., Belyaeva O.G., Plotnikov V.F., Puzyr' A.P. (1996) Study of biodegradation of microbial polyhydroxylalkanoates. Doklady Biological Sciences 350: 504-508.

22. Volova T.G., Gladyshev M.I., Trusova M.Y., Zhila N.O., Kartushinskaya M.V. (2004) Degradation of bioplastics in natural environment. Doklady Biological Sciences 397: 330-332..

23. VolovaT.G.,GladyshevM.I., TrusovaM.Y.,ZhilaN.O.(2006)Degradationof polyhydroxyalkanoates and the composition of microbial destructors under natural conditions. Microbiology 80 (5): 593 598.

24. VolovaT.G.,GladyshevM.I.,TrusovaM.Y.,ZhilaN.O.(2007)Degradationofpolyhydroxyalkanoates in eutrophic reservoir. Polym Degrad Stab 92: 580-586.

25. Volova T.G., Boyandin A.N., Vasiliev A.D (2010) Biodegradation of polyhydroxyalkanoates (PHAs) in tropical coastal waters and identification of PHA-degrading bacteria. Polym Degrad Stab 95: 2350-2359.

26. Volova T.G., Boyandin A.N., Vasil'ev A.D., Karpov V.A., Kozhevnikov I.V., Prudnikova S.V., Rudnev V.P., Büi Bá Xuån, V uViet D ung, Gitel'zon I.I. (2011) Biodegradation of polyhydroxyalkanoates (PHAs) in the South China Sea and identification of PHA-degrading bacteria. Microbiology 80 (2): 252-260.

27. Volova T., Kiselev E., Shishatskaya E., Zhila N., Boyandin A., Syrvacheva D., Vinogradova O., Kalacheva G., Vasiliev A., Peterson I. (2013) Cell growth and PHA accumulation from $\mathrm{CO}_{2}$ and $\mathrm{H}_{2}$ of a hydrogen-oxidizing bacterium, Cupriavidus eutrophus B-10646. Bioresource Technology 146: 215-222.

28. Volova T.G., Kiselev E.G., Vinogradova O.N., Nikolaeva E.D., Chistyakov A.A., Sukovatyi A.G., Shishatskaya E.I. (2014) A glucose-utilizing strain, Cupriavidus eutrophus B-10646: growth kinetics, characterization and synthesis of multicomponent PHAs. Plos One 9 (2): 1-15 - e87551..

29. Wen X., Lu X. (2012) Microbial degradation of poly(3-hydroxybutyrate-co-4-hydroxybutyrate) in soil. J Polym Environ 20: 381-387.

30. Weng Y.-X., Wang X.-L., Wang Y.-Z. (2011) Biodegradation behavior of PHAs with different chemical structures under controlled composting conditions. Polymer Testing 30: 372-380.

31. Williams S.F., Martin D.P., Horowitz D.M., Peoples O.P. (1999) PHA applications: addressing the price performance issue I. Tissue engineering. Int J Biol Macromol 25(1-3): 111-121. 